Boise State University

ScholarWorks

Geosciences Faculty Publications and

Presentations

Department of Geosciences

$1-2016$

Targeted Reflection-Waveform Inversion of Experimental GroundPenetrating Radar Data for Quantification of Oil Spills Under Sea

Ice

John H. Bradford

Boise State University

Esther L. Babcock

GeoTek Alaska, Inc.

Hans-Peter Marshall

Boise State University

David F. Dickins

DF Dickins Associates, LLC

This document was originally published by the Society of Exploration Geophysicists in Geophysics. Copyright restrictions may apply. doi: 10.1190/geo2015-0170 


\title{
Targeted reflection-waveform inversion of experimental ground-penetrating radar data for quantification of oil spills under sea ice
}

\author{
John H. Bradford ${ }^{1}$, Esther L. Babcock ${ }^{2}$, Hans-Peter Marshall ${ }^{1}$, and David F. Dickins ${ }^{3}$
}

\begin{abstract}
Rapid spill detection and mapping are needed with increasing levels of oil exploration and production in the Arctic. Previous work has found that ground-penetrating radar (GPR) is effective for qualitative identification of oil spills under, and encapsulated within, sea ice. Quantifying the spill distribution will aid effective spill response. To this end, we have developed a targeted GPR reflection-waveform inversion algorithm to quantify the geometry of oil spills under and within sea ice. With known electric properties of the ice and oil, we have inverted for oil thickness and variations in ice thickness. We have tested the algorithm with data collected during a controlled spill experiment using 500$\mathrm{MHz}$ radar reflection data. The algorithm simultaneously recovered the thickness of a 5-cm-thick oil layer at the base of the ice to within $8 \%$ of the control value, estimated the thickness of a 1-cm-thick oil layer encapsulated within the ice to within $30 \%$ of the control value, and accurately mapped centimeter-scale variations in ice thickness.
\end{abstract}

\section{INTRODUCTION}

Increased interest in oil and gas development in Arctic regions is driving the need to develop rapid and effective methods for oil spill characterization and remediation in the sea ice environment. Crude oil released from a subsea blowout, or a marine pipeline rupture, will rise through the water column to the surface. An ice sheet will trap the oil to form a layer at the base of the ice. Topography of the ice base may provide "reservoirs" to effectively contain spilled oil and thus determine the areal distribution of oil.
Spills during ice growth (typically October to April in many Arctic areas) may become encapsulated by new ice growth beneath the oil layer.

One potential tool for characterizing oil spills under and within sea ice is ground-penetrating radar (GPR). There is not extensive literature on sea ice profiling with GPR. Kovacs (1977) images the bottom of first-year ice up to $2 \mathrm{~m}$ thick and multiyear ice up to $6 \mathrm{~m}$ thick with a $100-\mathrm{MHz}$ pulsed radar system. Kovacs and Morey (1978) record ice-bottom reflections in first-year ice up to $2 \mathrm{~m}$ thick and multiyear ice more than $5 \mathrm{~m}$ thick using pulsed radar with a center frequency of $625 \mathrm{MHz}$. More recently, Galley et al. (2009) record ice-bottom reflections in first-year ice up to $1 \mathrm{~m}$ thick using 250-MHz and $1-\mathrm{GHz}$ antennas.

Bradford et al. (2008) use 800-MHz GPR antennas in a laboratory experiment and $500-\mathrm{MHz}$ antennas in a natural sea ice test to qualitatively locate crude oil trapped at the sea ice/water interface. Bradford et al. (2010) use a helicopter-mounted, 1-GHz radar to qualitatively identify oil spilled on the sea ice surface and buried by snow. An important caveat is that the electric conductivity of warm, thick ice (e.g., in the Beaufort Sea in late April through May) is too high for radar to penetrate effectively because of the high liquid brine content. Therefore, we expect that radar will be most effective as a spill response tool in the early to late winter period when the ice is cold. Critical for an effective cleanup response, however, is not only a spill location but also a quantitative assessment of the oil distribution.

Quantitative assessment is challenging due to the wavelength $\lambda$ of the GPR signal used in typical sea ice investigations relative to the thickness of an oil spill layer that might be encountered. In our experience, it is feasible to consistently image the base of first-year ice using a pulsed radar with a center frequency of $500 \mathrm{MHz}$. A typical relative dielectric permittivity $\varepsilon_{r}$ for crude oil is approximately three, yielding $\lambda=35 \mathrm{~cm}$ at $500 \mathrm{MHz}$.

Under-ice topography varies roughly by approximately $20 \%$ of the total ice thickness (Norcor Engineering and Research Ltd.,

First presented at the 2015 Arctic Technology Conference in Copenhagen, Denmark. Manuscript received by the Editor 11 March 2015 ; revised manuscript received 3 July 2015; published online 16 November 2015.

${ }^{1}$ Boise State University, Department of Geosciences, Boise, Idaho, USA. E-mail: jbradfor@boisestate.edu; hpmarshall@boisestate.edu.

${ }^{2}$ GeoTek Alaska, Inc., Anchorage, Alaska, USA. E-mail: estherbabcock@u.boisestate.edu.

${ }^{3}$ DF Dickins Associates, LLC, LaJolla, California, USA. E-mail: dfdickins@ @bcglobal.net.

(C) 2015 Society of Exploration Geophysicists. All rights reserved. 
1975). In midwinter, Arctic first-year ice has a thickness of approximately $1.5 \mathrm{~m}$; in which case, the maximum oil thickness we are likely to encounter is approximately $30 \mathrm{~cm}$. Even in this extreme case, the oil thickness is less than a wavelength of the radar signal at peak frequency. More often, the oil layer is likely to be substantially thinner; e.g., the topographic reservoir is not completely filled or the topographic variations are less than $30 \mathrm{~cm}$. Radar resolution limits are typically given in terms of the spatial separation between two reflection boundaries required to clearly identify separate peaks from the radar waves reflected from those boundaries. A resolution limit of $\lambda / 4$ at the dominant frequency of the radar pulse is often assumed but is probably overly optimistic; in field data, a more realistic rule of thumb is approximately $\lambda / 2$. Oil accumulations may often be well below this limit, e.g., a 5-cm-thick oil layer under a $50-\mathrm{cm}$-thick ice pack is approximately $\lambda / 7$ for a $500-\mathrm{MHz}$ radar signal. Thus, the oil-under-ice imaging problem will require thinlayer analysis in most cases. Model, field, and experimental GPR data analysis have shown significant variations in the amplitude, frequency, and phase of the reflected waveform as a function of the oil-layer thickness when a thin layer of oil is present at the base of the ice or on the surface of ice and covered by snow (Bradford et al., 2008, 2010). Although these previous studies are limited to qualitative interpretation of the data, they do suggest the potential to quantify oil-layer properties.

In recent years, several GPR researchers have made strides in quantitative investigation of thin-layer properties using a variety of different approaches. For example, Tsoflias and Becker (2008) use numerical models and field data to investigate amplitude and phase variations as a function of fracture aperture and fracture fluid conductivity for rock fractures as thin as $\lambda / 660$. They show a strong relationship between fluid conductivity, radar frequency, and radar reflection attributes, even for these extremely thin layers. Deparis and Garambois $(2009,2010)$ invert amplitude- and phasevariation-with-offset curves to accurately estimate the properties of the fill material in thin rock fractures. These studies have shown potential to quantify thin-layer properties using radar reflections, but only used a subset of the information contained in the radar data.

Waveform inversion methods have the potential to use all of the information carried by a GPR signal. They have become an area of active research in recent years for transmission data in borehole applications (Ernst et al., 2007; Klotzche et al., 2010, 2014) and for estimating near-surface soil properties from surface GPR data (Busch et al., 2012; Minet et al., 2012; Tran et al., 2012). In cryosphere applications, Schmid et al. (2015) show significant potential to obtain snowpack properties from global, full-wavefield inversion of GPR reflection data in the frequency domain. However, many challenges remain before field implementation is feasible.

A significant challenge in inverting surface GPR reflection data acquired with the antennas close to the surface is that the antenna response depends on surface electric impedance; a general solution requires inversion for source and receiver parameters at every location, making for an exceptionally poorly constrained problem. However, Babcock and Bradford (2015) show that estimating an effective source wavelet as part of the inversion for a limited window of the reflected wavefield in a targeted inversion approach can be effective in some cases. They used their approach to estimate the thickness and permittivity of layers containing nonaqueous phase liquid contaminants from surface GPR reflection data. Using numerical and field examples, they demonstrate that the layer parameters could be recovered with good accuracy for layers as thin as $\lambda / 10$.

Characterizing oil spills under or within sea ice is better constrained than the typical GPR inversion problem. Well-tested empirical relationships exist to estimate sea ice electric properties as a function of ice depth given inputs of temperature and salinity (Thomas and Dieckmann, 2010). If a sample is available, crude oil dielectric permittivity and electric conductivity can be quickly measured with readily available time-domain reflectometry (TDR) and conductivity probes. The base of the system is seawater at the melting point, and its properties are well known. The remaining unknown parameter is the oil-layer thickness. Here, we implement a targeted GPR reflection inversion algorithm for quantifying oil spill thickness directly under or within sea ice. Our algorithm simplifies a more general approach (Babcock and Bradford, 2015), and it is designed specifically for speed of computation, which is critical during an actual spill response. Using experimental data acquired during a controlled spill at the United States Army's Cold Region Research and Engineering Laboratory (CRREL) in New Hampshire, we demonstrate the ability to accurately quantify the thickness of a thin layer of oil encapsulated in the ice sheet and a thin layer trapped between the base of the ice and the seawater.

\section{THEORY AND/OR METHOD}

At present, the algorithm is $1 \mathrm{D}$ and uses a plane-wave source with the reflectivity method to compute the forward model. It is functional in cases in which a $1 \mathrm{D}$ approximation is reasonable; we address this limitation in the "Discussion" section. The reflectivity method is orders of magnitude faster than other full-waveform solutions, such as finite-difference or finite-element methods, and it is more accurate. Speed is a significant limitation for full-wave methods, but it is a key attribute that makes our reflectivity approach attractive. The forward model was previously described by Bradford et al. (2008), but it has been modified here to include frequency-dependent constitutive parameters. We include a brief summary of the algorithm for completeness. The forward model consists of two components: (1) a sea ice electric property model based on the measurements of the ice temperature and salinity and (2) a 1D wave propagator implemented using the reflectivity method. The inverse step operates in the time domain and minimizes the root-mean-square ( $\mathrm{rms}$ ) difference between a measured GPR trace and a modeled GPR trace within a limited time window centered about a targeted interval.

\section{Electric property model}

The properties that control electromagnetic wave propagation include the electric permittivity and electric conductivity, both of which are functions of frequency. Sea ice is a complex mixture of brine and ice crystals. In natural sea ice, the short axis of the crystals is aligned with predominant seawater current leading to azimuthal anisotropy in the ice electric properties. Furthermore, the electric properties depend on temperature and salinity. Because of this complexity, it is necessary to use a set of empirical relationships to derive the electric properties. For this study, we used an electric property algorithm based on the equations summarized by Morey et al. (1984) and reproduced in Appendix A. The algorithm proceeds as follows: 
1) Input the measured temperature $T$ and bulk salinity profile $S$.

2) Compute brine volume $V_{b}$ as a function of $T$ and $S$.

3) Compute the brine salinity $S_{b}$ as a function of $T$.

4) Compute the brine conductivity $\sigma_{b}$ as a function of $S_{b}$ and $T$.

5) Compute the complex electric permittivity of the brine $\varepsilon_{b}$ as a function of frequency using the Debye relaxation model.

6) Compute the ionic conductivity of the ice/brine mixture using Archie's law as a function of $V_{b}$ and $\sigma_{b}$, then output to the wave propagator.

7) Compute the complex permittivity of the mixture as a function of $V_{b}$, the complex permittivity of the brine $\varepsilon_{b}$, and the permittivity of crystalline ice $\varepsilon_{i}$, then output to the wave propagator.

\section{Wave propagator}

The reflectivity method is an exact analytical solution to the electromagnetic wave equation for plane waves propagating through a 1D medium (see Appendix B for the relevant equations). The radar response is computed in the frequency domain for a layered model using a recursion formula that computes the Green's function (Mueller, 1985; Loseth and Ursin, 2007). Although not used in this study, it is possible to extend the method to simulate localized sources as a superposition of plane-wave solutions. The model incorporates smoothly varying vertical changes in material properties by dividing the model into many thin layers with small changes between each layer. The layer discretization must be well below the scattering limit (approximately $\lambda / 10-\lambda / 30$ ) for the radar wavelet being modeled. The source for the model is a plane wave at normal incidence. We use a complex Gabor wavelet, which is a Gaussian-modulated cosine function that can simulate a variety of source wavelets by varying the amplitude, peak frequency, phase, and width of the modulating window (Morlet et al., 1982). We obtain the parameters for the source wavelet as part of the inversion process.

\section{Inversion algorithm}

Our targeted inversion algorithm minimizes the difference between the model and the experimental data, in a least-squares sense, over a limited time window that contains the reflection of interest. To locate the minima, we use the multiparameter Nelder-Mead simplex method (Nelder and Mead, 1965). The problem is highly nonlinear, with an oscillating solution space, and care must be taken to assure convergence to the global minimum. Our targeted approach minimizes the nonuniqueness and complexity of the inverse problem and maximizes the likelihood of convergence.

The effective wavelet emitted by the GPR is a complicated function that depends on the electronics of the system and the impedance of the surface material when the GPR antenna is located near the air/surface interface (Annan, 2005). In general, the surface impedance varies so that the effective wavelet emitted by the system is not fixed, generally not known, and difficult to measure. Rather than attempting to directly model all of the antenna and coupling complexities, our inversion process includes optimization for an effective source wavelet.

To begin, we estimate the ice electric properties based on the ice core measurements of temperature, salinity, and ice thickness. Using a trace acquired near the core location, we then invert for the Gabor wavelet parameters, which provide an estimate of the effec- tive source wavelet. In this initial inversion, we use all known information to constrain the solution, e.g., if there is snow on the surface, we would include snow thickness and density as a fixed parameter in the forward model. We allow the ice thickness to vary within a narrow range during the effective source optimization. This accounts for uncertainties in the inputs such as errors in the GPR time-zero correction, variability in the ice thickness, and a finite footprint for the radar. We then assume that the effective source wavelet does not vary within our survey area, implying that the surface impedance does not vary significantly.

To conduct the inversion in the suspected spill location, we first construct a starting model by inserting a layer or layers of oil within the ice and/or at the base of the ice depending on the spill conditions. The inversion then optimizes for oil layer(s) thickness, depth, and total ice thickness. We allow the measured ice property model to stretch or compress vertically to accommodate small variations in ice thickness. For purposes of this article, we assume that the electric properties of the oil can be measured from a sample. However, the inversion procedure can easily incorporate solving for the oil permittivity as an additional parameter (Babcock and Bradford, 2015).

\section{EXPERIMENTAL TEST}

The project used the Geophysical Research Facility at CRREL to develop a test sea ice sheet. This facility consists of a concrete basin, $18.25 \mathrm{~m}$ long $\times 6.7 \mathrm{~m}$ wide $\times 2 \mathrm{~m}$ deep, with a removable roof that maintains a growing ice cover in a refrigerated ambient environment and protects it from snow. Growth of the 80- to 95-cm-thick ice sheet occurred between December and February 2011.

The CRREL staff conducted two crude-oil spills in two separate containment areas: the first on 18 February prior to testing to allow the oil to become encapsulated by new ice growth and the second on 2 March during GPR data acquisition. In each case, an oil discharge hose was positioned in the center of a $4 \times 4 \mathrm{~m}$ containment hoop via a trolley system along the basin bottom. The containment hoops consisted of plastic sheeting frozen in place during ice growth. These hoops extended approximately $30 \mathrm{~cm}$ beneath the base of the ice to contain the oil. We measured the relative permittivity of the crude oil at approximately $0^{\circ} \mathrm{C}$ with a TDR probe and found it to be 3.1 .

For each spill, approximately $0.57 \mathrm{~m}^{3}$ of crude oil was discharged into each test hoop. This volume translates to an average film thickness of $3.6 \mathrm{~cm}$, but the actual distribution was nonuniform due to ice irregularity. On 4 March, following completion of the radar surveys, CRREL personnel documented the ice properties (temperature and salinity), ice thickness, and oil distribution through a series of cores and drillholes. Figure 1a shows ice thickness estimated by fitting a surface to drillhole measurements. From the estimated under-ice topography, we calculated oil thickness for the second spill using the known oil volume and assuming that the upper surface of the oil followed the under-ice topography and that the lower bound formed a horizontal surface with the water (Figure 1b). Note the irregular ice thickness distribution and the variable oil thickness ranging from approximately $0.5 \mathrm{~cm}$ to just under $6 \mathrm{~cm}$. Even over this small $4 \times 4 \mathrm{~m}$ area, the few centimeters of ice topography result in a highly irregular oil thickness distribution. 


\section{GPR data acquisition and processing}

We acquired data with a Sensors and Software PulseEKKO Pro system using shielded antennas with a manufacturer-reported peak frequency of $500 \mathrm{MHz}$ (Figure 2), Note that these antennas are designed to output the reported frequency when ground coupled with "typical" soil. In our data, the dominant frequency of the effective source wavelet did not vary significantly from the reported $500 \mathrm{MHz}$ (see the "Inversion procedure" section below). The transmitting and receiving antennas were held at a fixed offset of $23 \mathrm{~cm}$. Traces were acquired by triggering the system with an odometer wheel set to $5 \mathrm{~cm} /$ trace. In the postacquisition calibration, we found that the nominal trace spacing was $4.33 \mathrm{~cm}$. A total of 16 traces were vertically stacked at each trace location to improve the signal-to-noise ratio. Sparsely located profiles were acquired on an orthogonal grid with $20 \mathrm{~cm}$ between profiles along the tank axis and $100 \mathrm{~cm}$ between profiles in the cross-tank direction. We acquired profiles along the tank axis before and after oil injection, but we acquired cross-tank profiles only after oil injection when it was recognized that the ice had strong azimuthal electric anisotropy (see the "Initial observations" section below).

Initial processing of the GPR data consisted of a time-zero correction, DEWOW filter, and spherical spreading correction (note that this is only approximate in a vertically heterogeneous medium).

\section{Initial observations}

Profiles collected in line with the tank axis before and after introduction of oil beneath the ice show a substantial change in the basal reflectivity (Figure 3). There is an increase in amplitude and a significant phase rotation of the basal reflection when oil is present. Figure 4 shows two orthogonal radar profiles collected across the containment cell for the second spill: one collected in line with the tank axis ( $y$-direction) and the other collected orthogonal to the tank axis ( $x$-direction). Although unexpected at the beginning of the experiment, we observed strong azimuthal electric anisotropy, particularly evident as high attenuation in the inline profile. The average amplitude for the base-of-ice (BOI) reflection in the inline direction is only 0.22 that of the crossline direction. If we assume that the BOI would be completely extinguished if the GPR polarization were perfectly aligned with the direction of maximum attenuation, then the observed decrease in amplitude would indicate that the $x$ axis of our survey was rotated roughly $12^{\circ}$ from the direction of maximum ice electric conductivity. The profile collected in the cross-tank direction then, with field polarization parallel to the $y$-axis of the survey, was near optimal alignment with the principal axis of anisotropy. Therefore, we use data from this cross-tank profile for all subsequent analysis.

Instantaneous attributes computed along the cross-tank profile clearly correlate with the oil thickness across the cell (Figure 5). There is an obvious increase in the amplitude of the BOI that correlates with the increasing oil thickness near the center of the containment cell. Instantaneous phase and frequency also vary systematically with the changing oil thickness. These changes in the waveform are caused by interference between reflections from the top and bottom of the thin layer of oil. At $500 \mathrm{MHz}$, the in situ GPR wavelength is $34 \mathrm{~cm}$ in the oil with a relative permittivity of 3.1 . The maximum oil thickness of $6 \mathrm{~cm}$ is less than $\lambda / 5$, which is well below the $\lambda / 2$ conventional resolution limit. However, significant and measurable changes to the waveform occur well below this thickness.

A band of fine oil droplets approximately $1 \mathrm{~cm}$ thick was observed roughly $9 \mathrm{~cm}$ from the bottom of the ice throughout the tank (Figure 6). We believe that a very small percentage of oil drifted laterally as fine droplets beyond the skirt boundaries during the earlier oil injection and was encapsulated into the growing ice sheet throughout the tank. This layer produced a measurable reflection in the GPR data. Thus, we included the encapsulated layer in our background property model and as a parameter in the inversion.

\section{Inversion procedure}

The temperature and salinity for the background ice model were taken from an ice core collected near the center of the tank and outside the oil spill containment areas (Figure 7a and 7b). Within the core, temperature and salinity were measured nominally every $10 \mathrm{~cm}$. We interpolated these measurements onto a 5-mm spaced vertical profile to produce the electric property model for GPR simulation (Figure $7 \mathrm{c}$ and $7 \mathrm{~d}$ ).

To estimate the effective source wavelet (Figure 8a), we used a trace taken from an area outside the oil containment cells and selected a 3-ns window bounding the BOI for inversion (Figure 8b). We began with a trial-and-error approach to obtain starting parameters then inverted for the phase and amplitude to estimate the effective source wavelet (Table 1; Figure 8a). Within this source inversion, it was also necessary to invert for the ice thickness, and the thickness and position of the encapsulated oil sheen located above the base of the ice. For all inverse models, we minimize the rms difference between the model and experimental trace using
Figure 1. (a) Ice thickness estimated by fitting a surface to 21 drillhole measurements on a $20 \times 60$-cm grid. (b) Oil thickness is computed from the total volume of oil spilled with the upper surface following under ice topography and the lower surface forming a horizontal boundary with the water surface. The $\bullet$ symbol shows the location of ice thickness measurements, the asterisk * shows the location of the trace used for detailed inversion analysis, and the dashed line shows the location of the inverted GPR profile. The area within the solid box is the region free from containment skirt interference. Oil thickness is necessarily anticorrelated with ice thickness. Note that the $y$-direction is aligned with the tank axis.
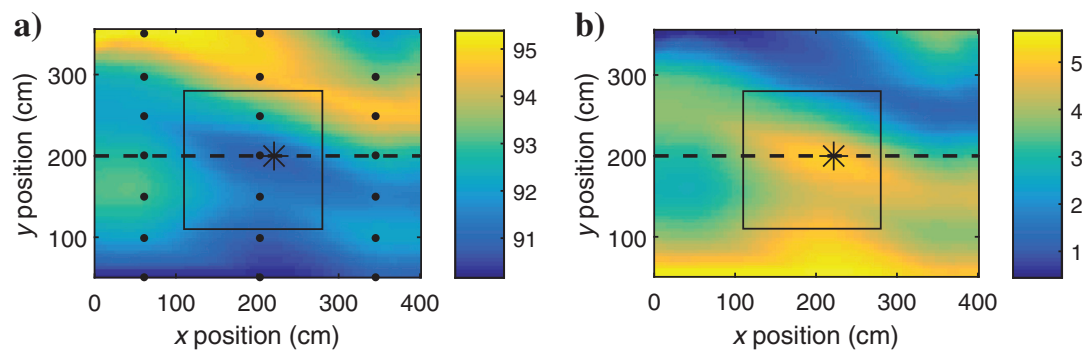
every sample within the 3-ns time window that bounds the BOI. The inversion procedure produced a model that fit the BOI to an $\mathrm{rms}$ difference of $13.4 \%$ relative to the maximum amplitude within the window (Figure $8 \mathrm{~b}$ ). The parameters derived from the inversion are shown in Table 1 and are in good agreement with the control data.

After having derived the effective source wavelet and background model as described above, we selected a trace from the center of the containment cell with oil at the base of the ice for detailed investigation (Figure 1). We first probed the inverse solution space by running a Monte Carlo simulation with 100,000 realizations drawn from uniform parameter distributions that spanned the physically plausible values (Figure 9a). Of 100,000 models, 61 solutions fit the experimental data between $12.7 \%$ and $14.4 \%$ rms amplitude difference, which we take to be close to the global minimum and assume that any solution falling into this range may be equally valid (all solutions falling into the bin with the smallest $\Delta_{\mathrm{rms}}$ in Figure 9a). We take the uncertainty in our subsequent inversions to be $\pm 1 / 2$ the range of parameter solutions that produced these 61 models.

To test the robustness of the inverse procedure, we ran the inversion using four different starting models. Starting model 1 consisted of the background model, but with a 3.6- $\mathrm{cm}$ layer of oil inserted between the ice and water. The $3.6-\mathrm{cm}$ layer is what would have been the thickness had the full volume of oil been uniformly distributed. Start model 2 consisted of the mean parameters taken from the 61 best fitting models from the Monte Carlo simulation described in the previous paragraph. Starting model 3 used the background model but assumed an initial oil thickness of $0 \mathrm{~cm}$. Finally, starting model 4 consisted of the background ice model with a 3.6$\mathrm{cm}$ oil layer at the BOI but left out the encapsulated oil sheen and in the subsequent inversion assumed that no oil sheen was present.

The final stage of inversion consisted of using the output model of the inversion at the central trace as a seed to invert for parameters along the rest of the profile. In this procedure, we start from the center and work outward in both directions, although the direction of travel is not important in this case. The optimized inverse model at each location becomes the starting model for the inversion at the

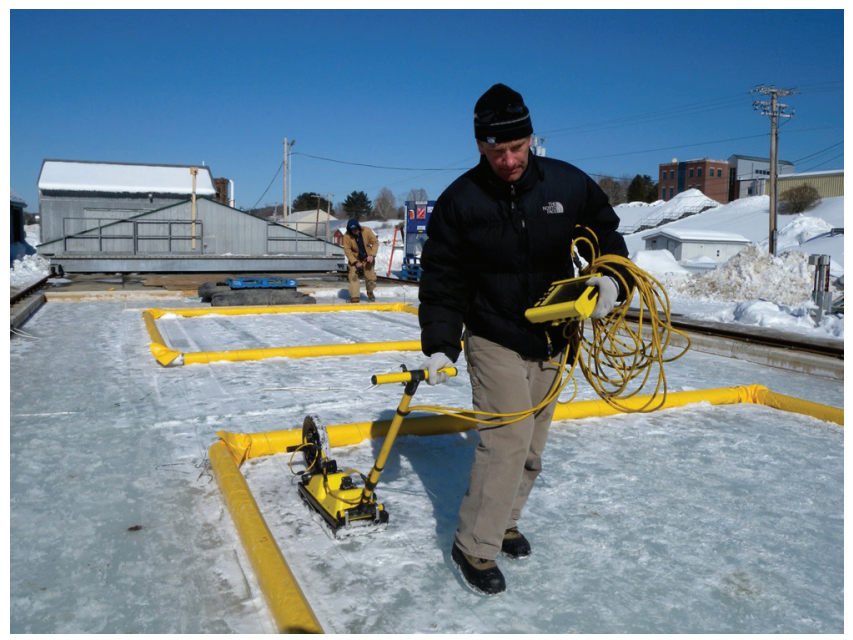

Figure 2. Photograph of the first author acquiring data along the tank axis with the $500-\mathrm{MHz}$ antenna set. The antennas are inside the containment hoop with oil under the ice.
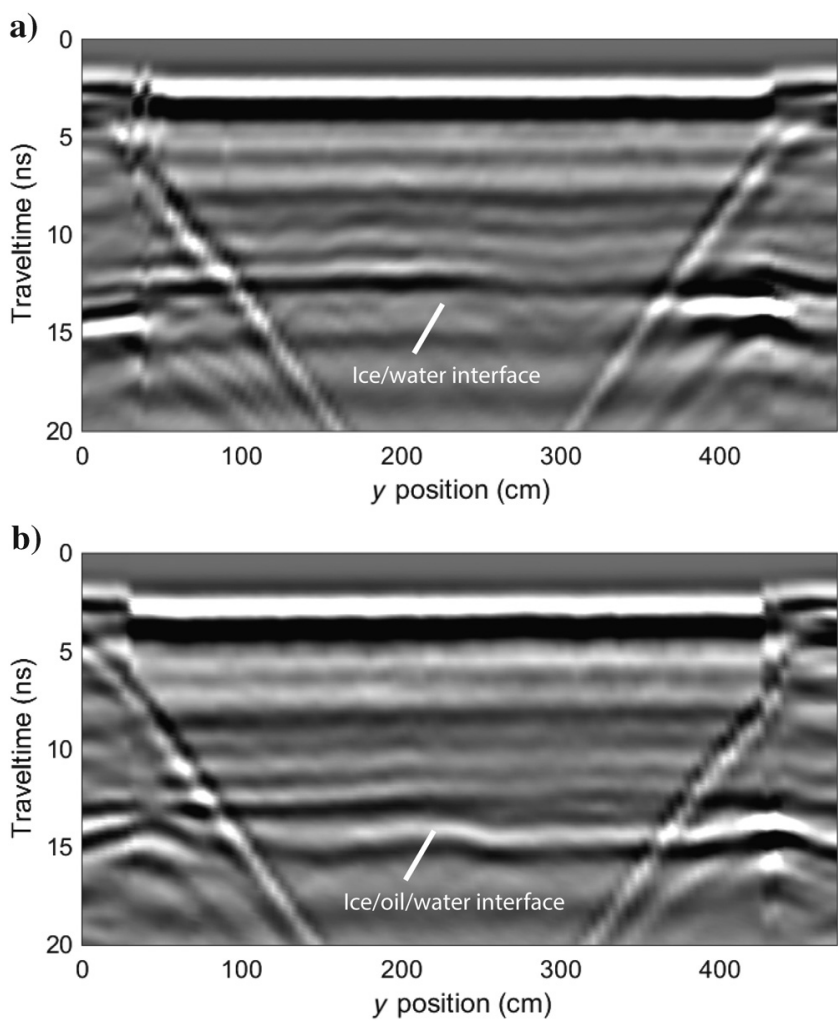

Figure 3. (a) Radar profile acquired prior to oil emplacement at the BOI (28 February 2011). The reflection from the thin (approximately $1 \mathrm{~cm}$ ) encapsulated layer is centered at approximately $11 \mathrm{~ns}$, although the BOI is just beneath this reflection, and it is close to the background noise level in this polarization. (b) After oil emplacement beneath the ice (2 March 2011), the combined ice/ $\mathrm{oil} / \mathrm{water}$ reflection is clearly differentiable and exhibits a significant change from the prespill profile in panel (a). The orthogonal polarization shows approximately fivefold improvement in signal to noise (see Figure 4).

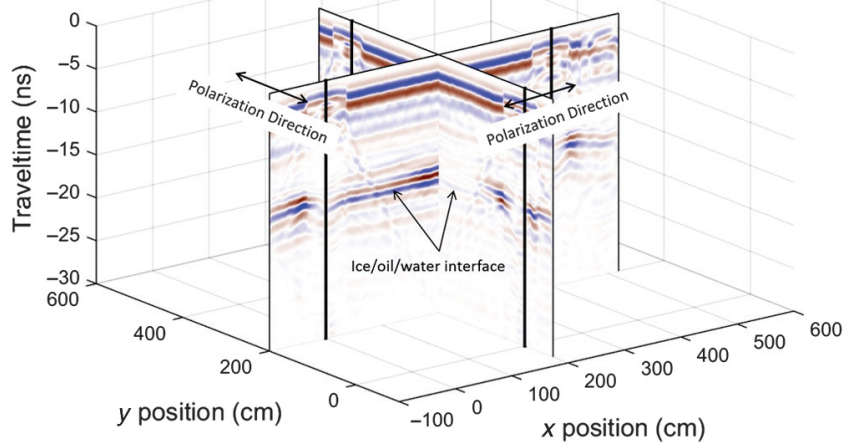

Figure 4. Orthogonal GPR profiles that intersect at the center of the containment hoop. The solid black lines indicate containment cell boundaries. Strong electric anisotropy is evident because the profile collected in the along-axis $(y)$ direction is strongly attenuated within the containment cell, whereas the profile collected in the cross-tank $(x)$ direction exhibits a high-amplitude reflection from the base of the ice. The profile acquired in the cross-tank direction is used for all subsequent analysis. The electric field polarization was oriented perpendicular to the profile orientation as indicated by the blue arrows. 
adjacent trace. This procedure maximized lateral coherence in the inverse solution. To avoid interference from scattering and potential ice anomalies caused by the containment skirts, the analysis is limited to the $2 \times 2 \mathrm{~m}$ area centered within the containment cell (Figure 1).

\section{RESULTS}

All four starting models led to inverse solutions that are close to the rms best-fit range described above (Figure 8c-8f) with starting models 1-3 leading to solutions that are visually indistinguishable having rms difference values close to the global minima. The estimated model parameters are reported in Table 2 . The poorest data fit was found with starting model 4 , which did not include the thin encapsulated oil sheen, but still converged to a reasonable estimate for the oil-layer thickness. All starting models led to solutions for the oil spill thickness that are within $16 \%$ of the thickness estimated from oil volume and ice topography calculations. Starting models 1 , 2 , and 4 produced solutions that are within $10 \%$ of the control value. All solutions for oil layer thickness are within the estimated uncertainty of the control thickness and within $5 \%$ of each other.

In addition, the inversion estimates from all starting models for the encapsulated oil sheen thickness are consistent with ice core measurements. The inverted oil sheen height above the base of the ice is approximately $4 \mathrm{~cm}$ lower than that outside of the test cell. This result is consistent with the observation that the ice thickness is lower in the central part of the test cell in which the inverted trace is taken, if the ice thickness was more uniform when the thin oil sheen was emplaced, then it should be closer to the BOI in areas of lower total ice thickness.

The results from the full profile inversion are similarly promising (Figure 10). The ice thickness estimates follow the same trend and are within estimated uncertainty of the ice thickness estimated from drillhole measurements. It is important to note here that the drillhole measurements are separated by $142 \mathrm{~cm}$ in the crossline direction, and therefore the details of ice topography are not well constrained. It is possible that the GPR inversion results are providing a more precise view of the ice bottom variability. Oil thickness estimates are in somewhat poorer agreement than ice thickness and are not within the uncertainty estimate on the left side of the profile. However, the trend is comparable with the control measure. Finally, the inversion estimates of encapsulated sheen thickness and depth are reasonable although there are no control measurements of these

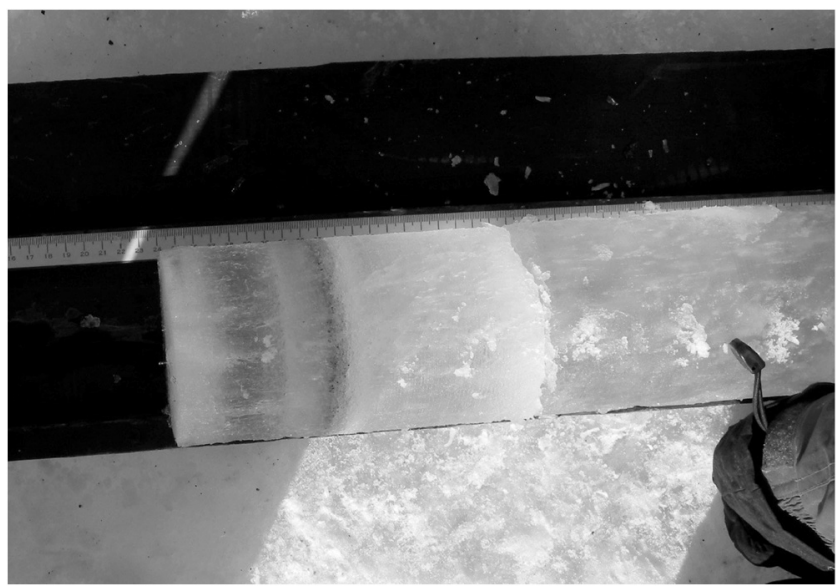

Figure 6. Photograph of an ice core taken from outside the containment cells showing a thin $(<1 \mathrm{~cm})$ sheen of oil droplets located approximately $9 \mathrm{~cm}$ above the base of the ice. This thin layer produced a measurable GPR response even at the relatively long wavelength of $25-30 \mathrm{~cm}$ of the $500-\mathrm{MHz}$ signal.
Figure 5. Instantaneous attributes taken from the cross-tank profile are shown in Figure 4. (a) Instantaneous amplitude (envelope function) image showing a clear amplitude increase toward the center of the test cell in which the oil spill is thickest (see Figure 1). (b) Instantaneous frequency and (c) instantaneous phase measured at the peak of the envelope function: both show systematic variation with oil thickness. Note the cell boundaries are located at $x=0$ and $x=400 \mathrm{~cm}$.
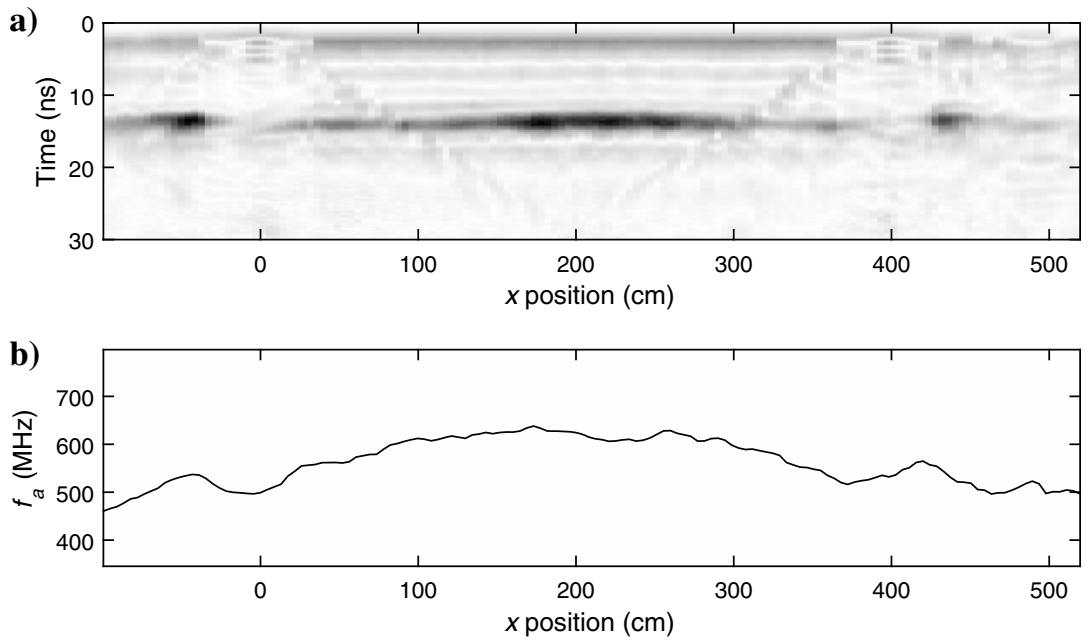

c)

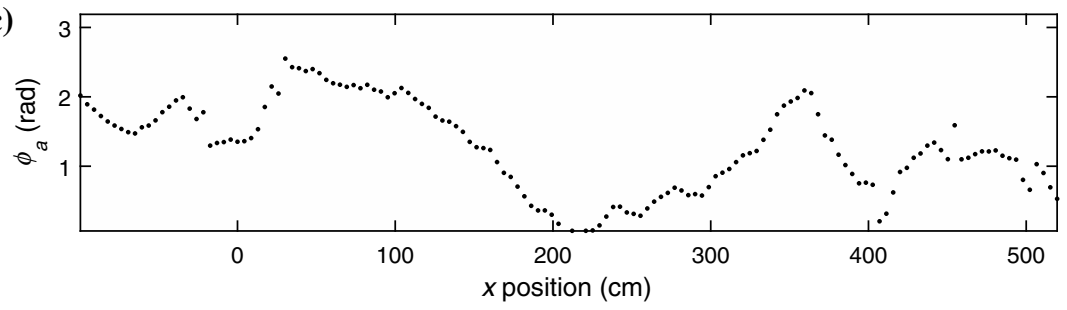


parameters within the test cell. The result does indicate that the inversion is laterally stable and produces results that are consistent with known details about the oil distribution.

\section{DISCUSSION}

That only $0.06 \%$ of the 100,000 simulations of possible solutions were within $1.3 \%$ of the global minimum indicates that the inverse solution to this problem is well constrained. The solution space is largely aided by the simplifications we made for this particular case that the background electric properties do not vary too much from a control location in which they are known and that the electric properties of the oil are known. We are left to invert for four parameters that define the 1D geometry over a limited depth interval. With these constraints, only a limited number of parameter combinations can fit the data.

Whether these parameter combinations are a realistic representation of reality is another question altogether. The answer depends on whether the assumptions we make about the physical system are reasonable. Perhaps the most critical step in the inversion process is source estimation. We invert for an effective source wavelet that
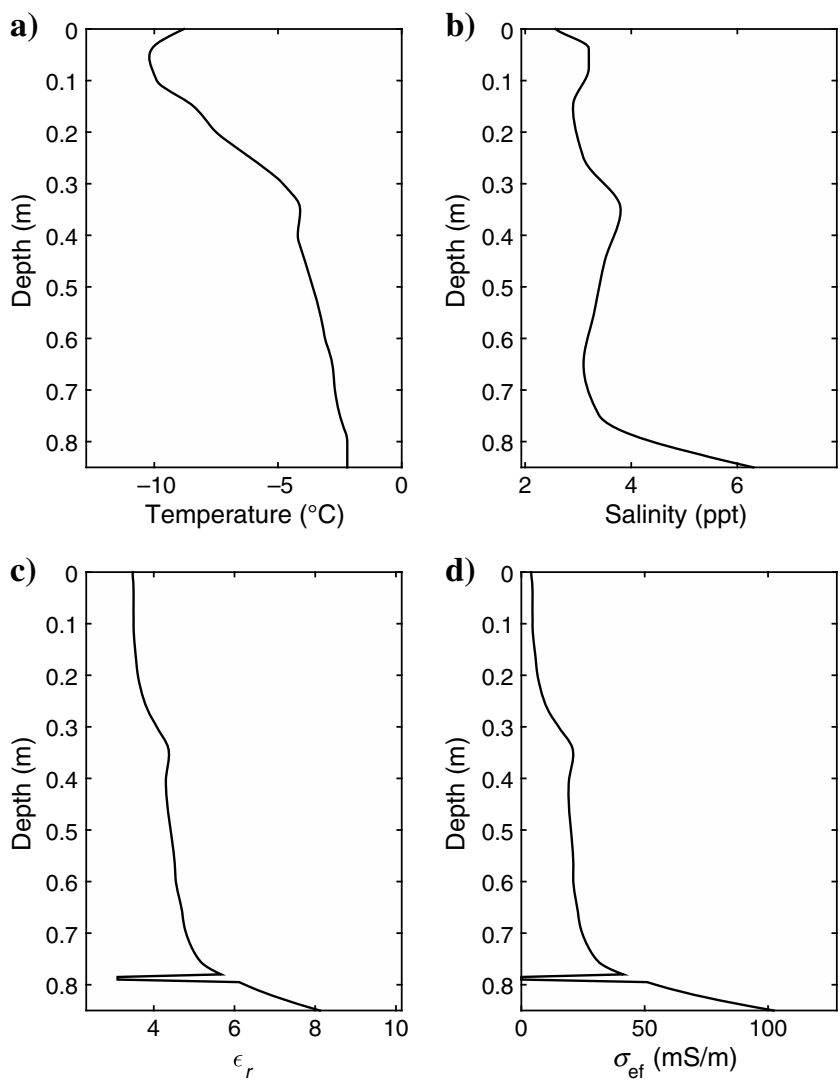

Figure 7. (a) Ice temperature and (b) ice salinity measured in an ice core just outside the containment cell. (c) Real relative permittivity and (d) real effective electric conductivity at $500 \mathrm{MHz}$ derived using the petrophysical transformation described in the text. The spike decrease in permittivity and conductivity just above the BOI is the result of inserting the thin sheen (approximately $1 \mathrm{~cm}$ thick) of encapsulated oil, which was present in the experimental ice due to an earlier spill, in a different area, in which a small amount of oil escaped its containment skirt. we assume accounts for propagation effects that are not included in our model but which occur above the target. These effects would include errors in the spreading correction and radiation patterns, errors in the petrophysical transform, and errors in the ice measurements themselves. If we accept that our effective source function largely accounts for these errors, then our inversion procedure depends entirely on things not changing too much between the location in which the calibration (source inversion) was done and the area of interest. The good match we observed for the CRREL test between the control data and inversion results indicates that our assumptions were valid for this controlled study. For field applications, we can expect that conditions will be more variable within a study area, so further testing in the field and a strategy for properly treating substantial lateral heterogeneity needs to be developed.

A second point to address is the anisotropy in the ice. It is typical to observe strong azimuthal electric anisotropy in sea ice associated with the preferential orientation of the ice crystal structure (Kovacs and Morey, 1978; Nyland, 2004). We have observed this in the field and in a series of controlled experiments at CRREL in which the only possible currents are weak convection currents associated with heat flow forced by heat exchangers at the base of the pool. In this
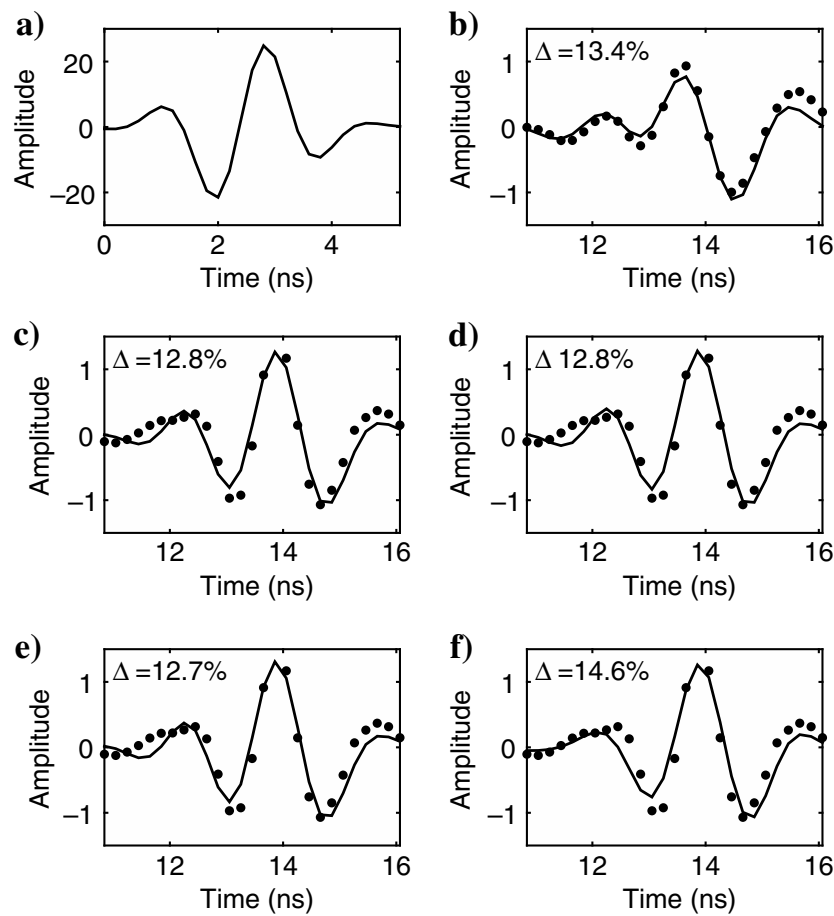

Figure 8. (a) Effective source wavelet estimated during the inversion for the trace shown in panel (b). (b) Inversion result for the background trace outside the test cell: The dotted line shows the experimental data, and the solid line shows the inversion model. Here, we inverted for the effective source wavelet, encapsulated oil sheen thickness, ice thickness, and encapsulated oil sheen depth. Inversions with (c) starting model 1, (d) starting model 2, and (e) starting model 3 yield slightly different fits to the data but do not differ significantly. (f) Start model 4 (assuming no encapsulated oil sheen) produces a significantly poorer fit to the data but finds an oil spill thickness that is within the estimated uncertainty of starting models $1-3$. See Table 2 for model parameters corresponding to the four solutions. The quantity $\Delta$ is the rms amplitude difference between the model and experimental trace within the targeted time window. 
study, it was fortuitous that our radar polarization was approximately aligned with the direction of minimum attenuation. However, general application will require polarimetric radar for

Table 1. Starting model parameters and inversion results for the control trace and effective source wavelet. The sheen is the encapsulated thin layer of fine oil droplets, $h$ indicates its height above the base of the ice, $D$ is the total ice thickness, $f_{\max }$ is the peak frequency of the source wavelet, $\varphi$ is the phase, $A$ is the amplitude, and $\Delta t$ is the Gaussian window width.

Ice parameters

Control data

\begin{tabular}{lrrr}
\hline & Start & Final & \\
\hline$h_{\text {sheen }}(\mathrm{cm})$ & 12.0 & 10.0 & 9.0 \\
$\Delta z_{\text {sheen }}(\mathrm{cm})$ & 0.5 & 1.3 & 1.0 \\
$D_{\text {ice }}(\mathrm{cm})$ & 93.2 & 93.8 & 93.2 \\
\hline
\end{tabular}

Source parameters

\begin{tabular}{lccc}
\hline & Start & Final & \\
\hline$f_{\max }(\mathrm{MHz})$ & 500 & 500 & - \\
$\Phi(\mathrm{rad})$ & 1.04 & 1.18 & - \\
$A$ & 120 & 110 & - \\
$\Delta t(\mathrm{~ns})$ & 2.5 & 2.5 & - \\
\hline
\end{tabular}

correct characterization of the ice. Modern multichannel radar systems can be configured appropriately, and we have recently demonstrated the efficacy of such a system through field and laboratory measurements (Babcock et al., 2015).

We assumed that our system is $1 \mathrm{D}$ and can be represented with a plane-wave model at normal incidence. With a $23-\mathrm{cm}$ sourcereceiver offset and 90-cm-thick ice, the angle-of-incidence at the $\mathrm{BOI}$ is $7.6^{\circ}$. This angle corresponds to a change in the reflection coefficient of only $0.4 \%$ from normal incidence, so the assumption of normal incidence is reasonable. The far-field assumption inherent in the plane-wave model is more difficult to address. The lower bound of the far-field region is generally accepted to be the Fraunhofer distance, which is defined as $2 D^{2} / \lambda$, where $D$ is the length of the dipole antenna (Balanis, 2005). With a mean sea ice relative permittivity of 4.35 and nominal frequency of $500 \mathrm{MHz}$, we have a $\lambda=29 \mathrm{~cm}$. Our antenna length is $18 \mathrm{~cm}$ giving a Fraunhofer distance of $22 \mathrm{~cm}$. Hence, at a depth of $90 \mathrm{~cm}$, the BOI is well beyond the far-field transition. The final consideration here is the antenna radiation pattern, which varies by take-off angle from the surface. Arcone (1995) describes the far-field radiation pattern for physical antennas in detail. In our case, with the antennas in the parallel broadside configuration (TE mode), the infinitesimal dipole approximation (Engheta et al., 1982) for a takeoff angle of $7.6^{\circ}$ from vertical yields an amplitude difference of $2 \%$ relative to vertical takeoff. The directional dependence for physical antennas is even smaller over this range, and it is evident that the impact of antenna directionality is not significant in our case.

Perhaps the bigger problem for adapting our approach to field conditions is the assumption of lateral heterogeneity. Specifically,
Figure 9. Results of Monte Carlo simulation. (a) Histogram of rms amplitude difference between inverse model and a single experimental trace for all 100,000 simulations. The minimum bin contains solutions that lie between $12.7 \%$ and $14.4 \% \mathrm{rms}$ difference, and we assume that this represents solutions close to the global minimum. (b) Oil spill thickness, (c) oil sheen thickness, and (d) oil sheen height above the BOI for all solutions that fit the data to less than $14.4 \%$ rms difference. a)

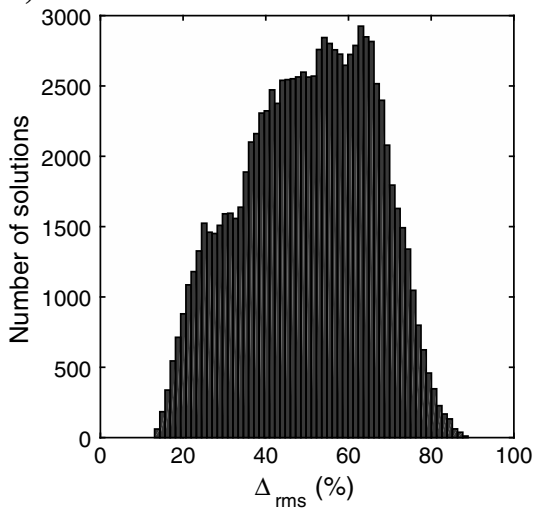

b)

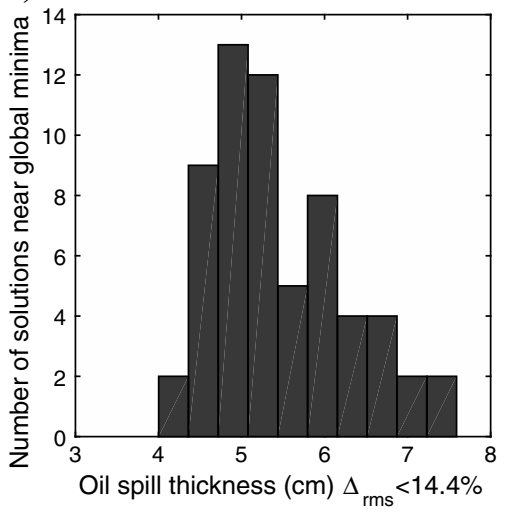

c)

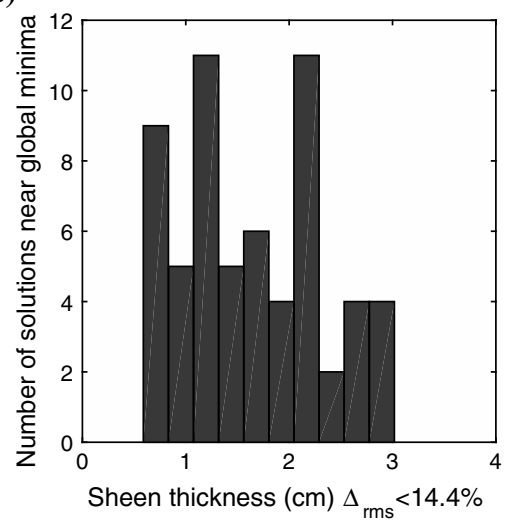

d)

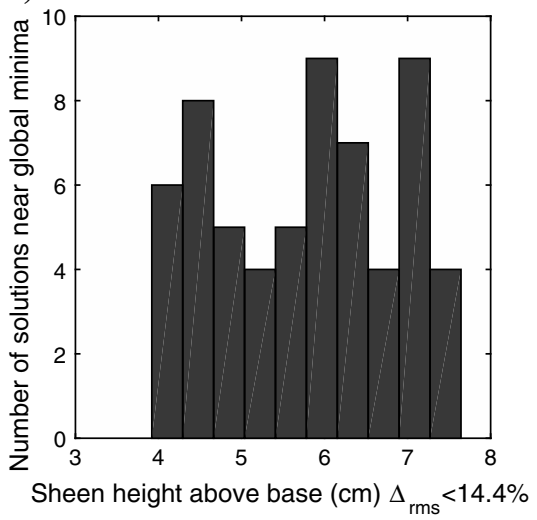


we assume that all reflections are almost horizontal and planar. Lateral roughness on the scale of a wavelength will generate nonspecular reflections, and dipping reflectors will violate the assumption of normal incidence: Both violate the assumptions of our model and have the potential to cause the inversion to fail. We can get an indication of this effect by examining the results of our inversion near the edges of the containment cell where there is scattering from the skirts. Figure 11 shows the experimental data and the corresponding profile generated from the laterally seeded 1D inversions. The model profile well represents the experimental data, particularly at the BOI and in the center of the containment cell.

The inversion fails at the right and left sides of the profile where scattering from the containment skirts is evident. Near the edges, the inversion tries to fit a 2D wavefield with a $1 \mathrm{D}$ model, which can sometimes provide a good fit to the data but not with a physically plausible model. The 1D approximation will be appropriate for field conditions in some cases, but a general solution will require adaptation to a 2D or 3D anisotropic inverse model. This adaptation will require substantially greater complexity in the formulation and associated computation. However, full-wavefield inversion is a rapidly advancing area of research, particularly oil exploration, and many of these technologies may be adapted for radar applications in the future.

\section{CONCLUSIONS}

Targeted full-waveform inversion appears promising for quantifying the thickness of oil spills that are trapped within ice and at the ice/water interface. By constraining the inversion through measurements of ice temperature and salinity along with oil permittivity, we

Table 2. Starting parameters and inversion results for a trace collected at the center of the oil spill containment cell. Four different starting models were used to test the robustness of the inversion. Each inversion finds a different local minimum in the vicinity of the starting model, but all inversions converge to a set of solutions with a very small range. The thickness of the oil spill is especially well-constrained with all solutions falling within $5 \%$ of each other.

\begin{tabular}{|c|c|c|c|c|c|c|c|c|c|}
\hline & \multicolumn{2}{|c|}{ Model 1} & \multicolumn{2}{|c|}{ Model 2} & \multicolumn{2}{|c|}{ Model 3} & \multicolumn{2}{|c|}{ Model 4} & \multirow[b]{2}{*}{ Control data } \\
\hline & Start & Final & Start & Final & Start & Final & Start & Final & \\
\hline$h_{\text {sheen }}(\mathrm{cm})$ & 10.0 & 5.6 & 5.9 & 5.9 & 10 & 5.1 & - & - & - \\
\hline$\Delta z_{\text {sheen }}(\mathrm{cm})$ & 1.3 & 1.4 & 1.7 & 1.5 & 1.3 & 1.7 & - & - & - \\
\hline$D_{\text {ice }}(\mathrm{cm})$ & 93.8 & 90.2 & 89.9 & 90.0 & 93.8 & 89.6 & 93.8 & 91.5 & 90.8 \\
\hline$\Delta z_{\text {oil }}(\mathrm{cm})$ & 3.5 & 5.4 & 5.5 & 5.5 & 0.0 & 5.8 & 3.5 & 5.5 & 5.0 \\
\hline
\end{tabular}
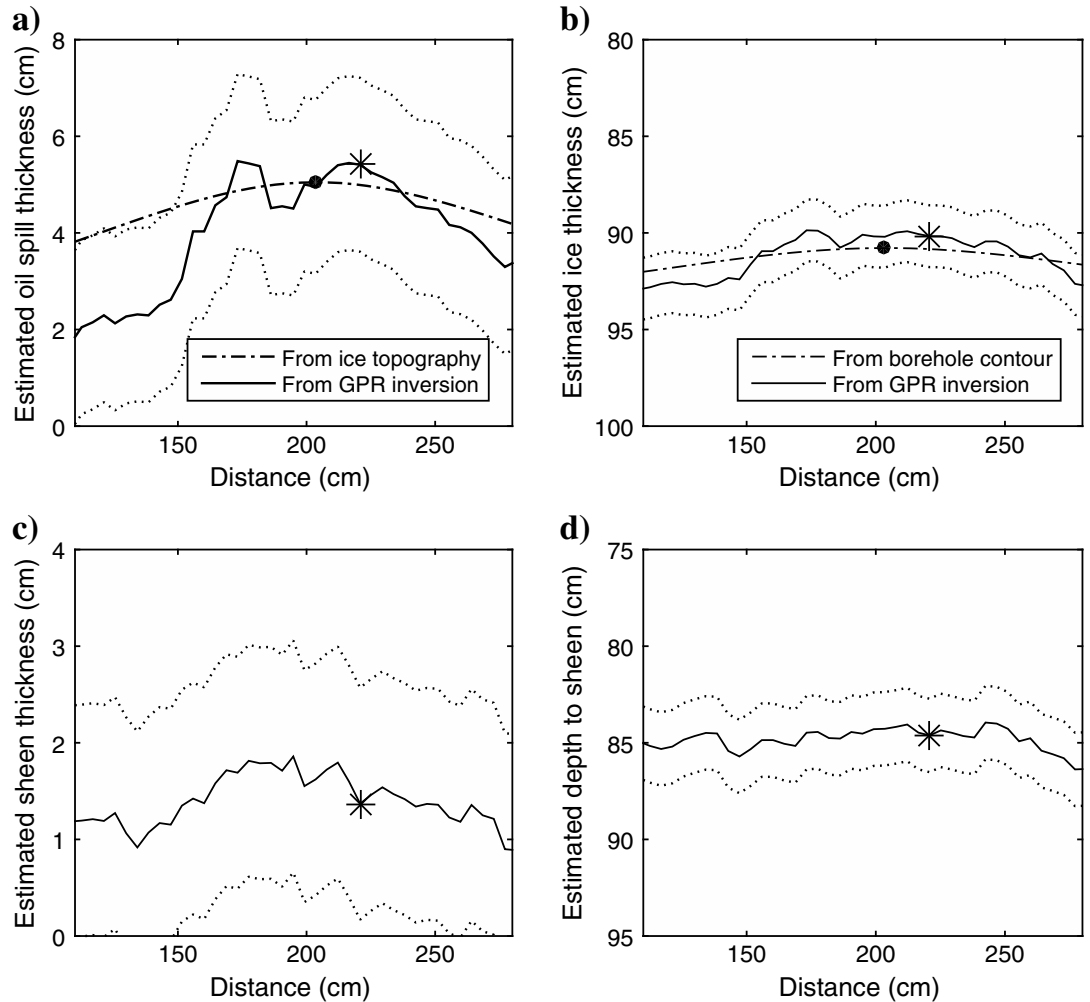

Figure 10. Results of inversion along full profile: shows the location of the ice thickness measurement, and $*$ shows the location of the trace used for detailed analysis and the model parameters used to seed the full profile inversion. The dotted lines show the uncertainty bounds estimated from the Monte Carlo simulation. (a) Oil spill thickness is close to the estimated uncertainty at all locations and varies from the value estimated from ice topography measurements by only $8 \%$ at the center of the test cell. (b) GPR estimated ice thickness is variable but is within the uncertainty of that contoured from ice thickness measurements. (c) Estimated encapsulated oil sheen thickness, which remains roughly constant and (d) at the same depth, across the profile. 


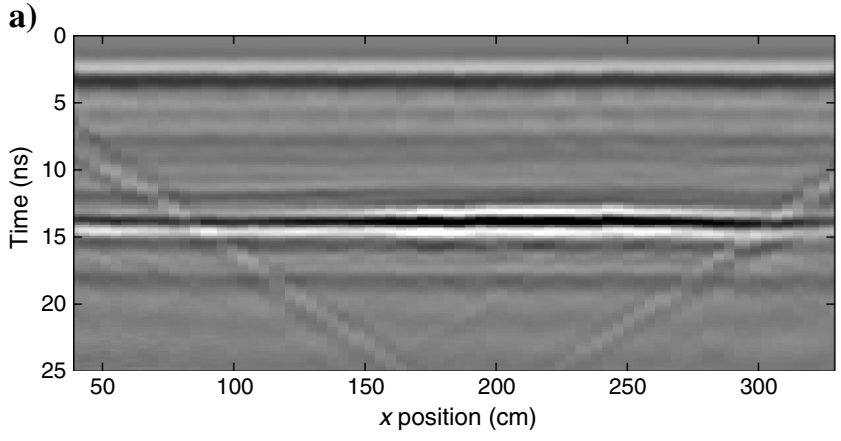

b)

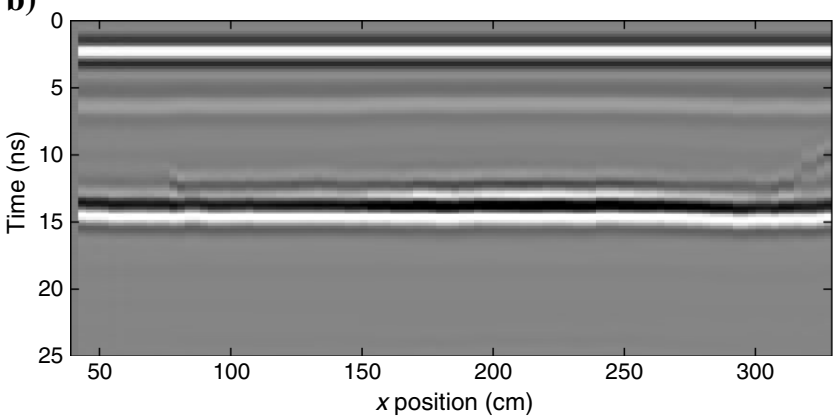

Figure 11. (a) Experimental data through the center of the cell and (b) the modeled profile from the inversion result. The effect of scattering from the containment skirts is evident from $x=75$ to $x=$ $110 \mathrm{~cm}$ and from $x=290$ to $x=325 \mathrm{~cm}$. Because the inversion is $1 \mathrm{D}$, it cannot properly account for this scattering. The inversion finds a reasonable fit to the data in these areas but fails to produce a physically realistic model because it tries to fit a $1 \mathrm{D}$ model to the 2D wavefield. Therefore, the 1D assumption is only a good approximation between $x=110$ and $x=290 \mathrm{~cm}$.

limit the number of parameters for which we must invert. In many cases, it will be feasible to make these measurements in the field during a spill response or estimated from weather conditions and historical data. The end result is less nonuniqueness in the solution so that a well-defined set of parameters can be found quickly. The simple 1D inversion approach presented in this study is very fast, which is desirable for a spill response tool when the response time is critical. The inversion worked well in our controlled experiment. Sea ice growing in the ocean can be significantly more complicated with areas of rough, broken ice, variable snow cover, and a more irregular distribution of brine. For more general application, future work will need to be directed toward assessing and accounting for $2 \mathrm{D}$ and $3 \mathrm{D}$ heterogeneity and will perhaps require $2 \mathrm{D}$ and $3 \mathrm{D}$ inversions that include ice anisotropy.

\section{ACKNOWLEDGMENTS}

We thank L. Zabilansky and the crew at CRREL's ice engineering lab for growing the ice, conducting the oil spills, and supporting logistics for the project. Review comments from S. Arcone, J. Lucius, and an anonymous reviewer are much appreciated and helped to improve the manuscript. The United States Bureau of Ocean Management: Regulation and Enforcement (now BSEE), Alaska Clean Seas, Shell, ConocoPhillips, and Statoil funded this project. Additional financial support was provided by the United States National Science Foundation under grant no. EAR 0943710.

\section{APPENDIX A EQUATIONS FOR ICE PROPERTIES}

We use the simple equation given by Frankenstein and Garner (1967) to calculate the volumetric brine fraction as a function of temperature and salinity:

$$
V_{b}=S\left(0.532+\frac{49.185}{T}\right)
$$

where $S$ is the bulk ice salinity in parts per thousand and $T$ is the temperature in ${ }^{\circ} \mathrm{C}$. Equation $\mathrm{A}-1$ is valid in the temperature range from -0.5 to $-22.9^{\circ} \mathrm{C}$. Then, to calculate the ionic conductivity of the brine, we use the equations given by Stogryn (1971) for $\mathrm{NaCl}$ solutions, shown here in the form presented by Morey et al. (1984):

$$
\begin{aligned}
& \sigma_{\mathrm{NaCl}}(T, N)=\sigma_{\mathrm{NaCl}}(25, N) \\
& \times\left[\begin{array}{l}
1.000-1.962 \times 10^{-2} \Delta+8.08 \times 10^{-5} \Delta^{2} \\
-\Delta N\left\{3.020 \times 10^{-5}+3.922 \times 10^{-5} \Delta+N\left(1.721 \times 10^{-5}-6.584 \times 10^{-6} \Delta\right)\right\}
\end{array}\right],
\end{aligned}
$$

where $\Delta=25-T$ and

$$
\begin{aligned}
\sigma_{\mathrm{NaCl}}(25, N)= & N\left[10.394-2.3776 N+0.68258 N^{2}\right. \\
& \left.-0.13538 N^{3}+1.0086 \times 10^{-2} N^{4}\right],
\end{aligned}
$$

with the normality $N$ given by

$N=S_{b}\left[1.707 \times 10^{-2}+1.205 \times 10^{-5} S_{b}+4.058 \times 10^{-9} S_{b}^{2}\right]$.

The value $S_{b}$ is the brine salinity, and equation A-5 is valid from $0<\mathrm{S}_{b}<260$. The brine salinity is calculated as a function of temperature described below (Assur, 1960):

$$
\begin{aligned}
& S_{b}=9.65-14.8 T ; \quad-8.2 \leq T \leq-2.0^{\circ} \mathrm{C} \\
& S_{b}=78.11-6.60 T ; \quad-22.9 \leq T \leq-8.2^{\circ} \mathrm{C} .
\end{aligned}
$$

To obtain the complex permittivity of the brine, we use the Debye model (Debye, 1945), which gives the real and imaginary parts of the relative permittivity $\left(\tilde{\varepsilon}_{b}=\varepsilon_{b}^{\prime}+j \varepsilon_{b}^{\prime \prime}\right)$ as

$$
\varepsilon_{b}^{\prime}=\varepsilon_{\infty}+\frac{\varepsilon_{s}-\varepsilon_{\infty}}{1+\omega^{2} \tau^{2}}
$$

and

$$
\varepsilon_{b}^{\prime \prime}=\frac{\left(\varepsilon_{s}-\varepsilon_{\infty}\right) \omega \tau}{1+\omega^{2} \tau^{2}},
$$

where $\omega$ is the angular frequency, $\varepsilon_{s}$ and $\varepsilon_{\infty}$ are the permittivities at DC and optical frequencies, respectively, and $\tau$ is the relaxation time. Stogryn and Desargant (1985) give the following equations to calculate the Debye parameters for brine as a function of temperature: 


$$
\begin{gathered}
\varepsilon_{s}=\frac{939.66-19.068 T}{10.737-T}, \\
\varepsilon_{\infty}=\frac{82.79+8.19 T^{2}}{15.68+T^{2}},
\end{gathered}
$$

and

$$
\begin{aligned}
2 \pi \tau= & 0.10990+0.13603 \times 10^{-2} T+0.20894 \times 10^{-3} T^{2} \\
& +0.28167 \times 10^{-5} T^{3} .
\end{aligned}
$$

With the conductivity and complex permittivity of the brine given by equations A-2, A-8, and A-9, we use the known properties for ice at radar frequencies $\left(\varepsilon_{i}=3.16\right.$ and $\left.\sigma_{i}=0\right)$ and assume that the ice is fully brine saturated to calculate the properties of the bulk ice/ brine mixture using the complex refractive index method (CRIM) (Wharton et al., 1980)

$$
\tilde{\varepsilon}=\left[\left(1-V_{b}\right) \sqrt{\varepsilon_{i}}+V_{b} \sqrt{\tilde{\varepsilon}_{b}}\right]^{2}
$$

and Archie's law (Knight and Endres, 2005)

$$
\sigma=\sigma_{\mathrm{NaCl}} V_{b}^{m}
$$

where the Archie's law exponent $m$ is set to 1.75 for the case in which the ice is columnar (Morey et al., 1984). We find that the CRIM equation is in good agreement with our field measurements when the field is aligned with the direction of minimum attenuation. Alternatively, we use the anisotropic formulation given by Taylor (1965).

\section{APPENDIX B}

\section{EQUATIONS FOR THE WAVE PROPAGATOR}

We use the reflectivity method to calculate the Green's function in our forward model. It is an exact analytical solution to the prob-

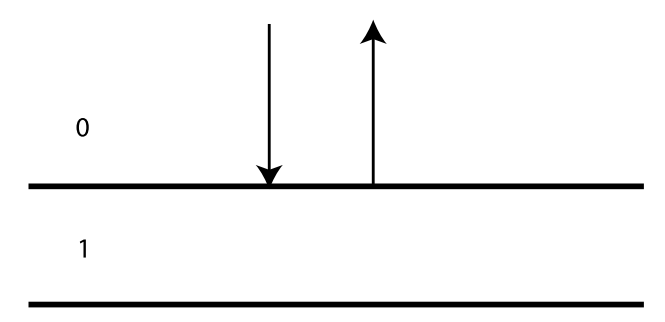

2

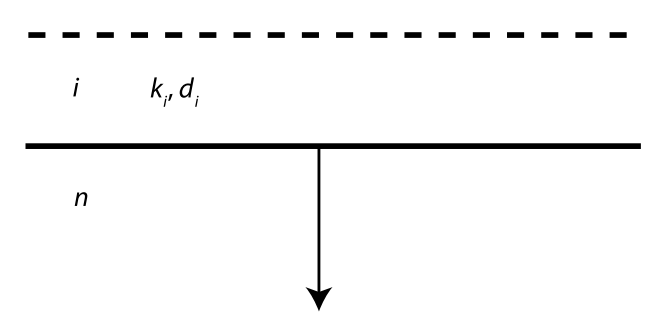

Figure B-1. Diagram showing the layer configuration for the reflectivity model. lem of a plane electromagnetic wave incident on a stack of horizontal layers. Here, we give the recursion formula presented by Mueller (1985), which was formulated for shear-horizontal seismic waves but has exactly the same form for our case of horizontally polarized electromagnetic waves. The equations are

$$
\begin{gathered}
R R=M B_{0}, \\
M B_{i}=r_{i+1}^{d}+\frac{t_{i+1}^{d} t_{i+1}^{u} M T_{i+1}}{1-r_{i+1}^{u} M T_{i+1}}, \quad i=n-1, \\
n-2, \ldots, 0, \\
M T_{i}=M B_{i} e^{-2 j \tilde{k}_{i} d_{i}},
\end{gathered}
$$

where the system consists of a stack of $n$ layers as shown in Figure B-1. The value $R R$ gives the wavefield reflected from the top of the stack of layers with a source at normal incidence from above. The variables $r$ and $t$ indicate the normal-incidence Fresnel reflection and transmission coefficients, respectively, the superscripts $d$ and $u$ indicate down- and upgoing waves, respectively, $j=\sqrt{-1}, k$ is the complex wavenumber, and $d$ is the layer thickness. The calculation proceeds from the bottom up, and one sets $M T_{n}=0$ in equation A-4 for the first iteration. The reflection and transmission coefficients $r_{i+1}$ and $t_{i+1}$ are calculated at the boundary separating the $i$ and $i+1$ layers. The complex wavenumber is calculated using the complex permittivity and ionic conductivity of the bulk ice/brine mixture as given in Appendix A. The solution to Maxwell's equations in a lossy medium gives

$$
\tilde{k}^{2}=\mu_{0} \tilde{\varepsilon} \varepsilon_{0} \omega^{2}+j \mu_{0} \sigma \omega
$$

with $\mu_{0}$ and $\varepsilon_{0}$ equal to the magnetic permeability and permittivity of free space, respectively.

\section{REFERENCES}

Annan, A. P., 2005, Ground-penetrating radar, in D. K. Butler, ed., Nearsurface geophysics: SEG, 357-438.

Arcone, S. A., 1995, Numerical studies of the radiation patterns of resistively loaded dipoles: Journal of Applied Geophysics, 33, 39-52, doi: 10.1016/ 0926-9851(95)90028-4.

Assur, A., 1960, Composition of sea ice and its tensile strength: United States Army Cold Regions Research and Engineering Laboratory, Research Report 44.

Babcock, E. L., and J. H. Bradford, 2015, Reflection waveform inversion of ground-penetrating radar data for characterizing thin and ultrathin layers of nonaqueous phase liquid contaminants in stratified media: Geophysics, 80, no. 2, H1-H11, doi: 10.1190/geo2014-0037.1.

Babcock, E. L., J. H. Bradford, and C. Hall, 2015, Electrical anisotropy in sea ice and a dual-polarization radar system to mitigate the effects of preferential attenuation in imaging sea ice: Cold Regions Science and Technology, 118, 105-111, doi: 10.1016/j.coldregions.2015.06.012.

Balanis, C. A., 2005, Antenna theory: Analysis and design, 3rd ed.: John Wiley \& Sons, Inc.

Bradford, J. H., D. F. Dickins, and P. J. Brandvik, 2010, Assessing the potential to detect oil spills in and under snow using airborne groundpenetrating radar: Geophysics, 75, no. 2, G1-G12, doi: 10.1190/1 .3312184.

Bradford, J. H., D. F. Dickins, and L. Liberty, 2008, Locating oil spills under sea ice using ground-penetrating radar: The Leading Edge, 27, 14241435, doi: 10.1190/1.3011014.

Busch, S. J., J. Van der Kruk, J. Bikowski, and H. Vereecken, 2012, Quantitative conductivity and permittivity estimation using full-waveform inversion of on-ground GPR data: Geophysics, 77, no. 6, H79-H91, doi: 10 .1190/geo2012-0045.1.

Debye, P. J., 1945, Polar molecules: Dover Publishing Inc. 
Deparis, J., and S. Garambois, 2009, On the use of dispersive APVO GPR curves for thin-bed properties estimation: Theory and application to fracture characterization: Geophysics, 74, no. 1, J1-J12, doi: 10.1190/ 1.3008545 .

Deparis, J., and S. Garambois, 2010, Inversion methodology of dispersive amplitude and phase versus offset of GPR curves (DAPVO) for thin beds, in R. D. Miller, J. H. Bradford, and K. Holliger, eds., Advances in nearsurface seismology and ground-penetrating radar: SEG, 219-232.

Engheta, N., C. H. Papas, and C. Elachi, 1982, Radiation patterns of interfacial dipoles: Radio Science, 17, 1557-1566, doi: 10.1029/ RS017i006p01557.

Ernst, J. R., A. G. Green, H. Maurer, and K. Holliger, 2007, Application of a new 2D time-domain full-waveform inversion scheme to crosshole radar data: Geophysics, 72, no. 5, J53-J64, doi: 10.1190/1.2761848.

Frankenstein, G., and R. Garner, 1967, Equations for determining the brine volume of sea ice from -0.5 to -22.9 C: Journal of Glaciology, 48, 943 944.

Galley, R. J., M. Trachtenberg, A. Langlois, D. G. Barber, and L. Shafai, 2009, Observations of geophysical and dielectric properties and ground penetrating radar signatures for discrimination of snow, sea ice and freshwater ice thickness: Cold Regions Science and Technology, 57, 29-38, doi: 10.1016/j.coldregions.2009.01.003

Klotzche, A., J. Van der Kruk, J. Bradford, and H. Vereecken, 2014, Detection of spatially limited high-porosity layers using crosshole GPR signal analysis and full-waveform inversion: Water Resources Research, 50, 6966-6985, doi: 10.1002/2013WR015177.

Klotzche, A., J. Van der Kruk, G. A. Meles, J. Doetsch, H. Maurer, and N. LInde, 2010, Full-waveform inversion of cross-hole ground-penetrating radar data to characterize a gravel aquifer close to the Thur River, Switzerland: Near Surface Geophysics, 8, 635-649, doi: 10.3997/1873-0604 .2010054

Knight, R. J., and A. L. Endres, 2005, An introduction to rock physics principles for near-surface geophysics, in D. K. Butler, ed., Near-surface geophysics: SEG, 31-70.

Kovacs, A., 1977, Sea ice thickness profiling and under-ice oil entrapment: Presented at the 9th Annual Offshore Technology Conference.

Kovacs, A., and R. M. Morey, 1978, Radar anisotropy of sea ice due to preferred azimuthal orientation of the horizontal $c$-axes of ice crystals: Journal of Geophysical Research, 83, 6037-6046, doi: 10 .1029/JC083iC12p06037.

Loseth, L. O., and B. Ursin, 2007, Electromagnetic fields in planarly layered anisotropic media: Geophysical Journal International, 170, 44-80, doi: 10 $.1111 /$ j.1365-246X.2007.03390.x.

Minet, J., P. Bogaert, M. Vanclooster, and S. Lambot, 2012, Validation of ground-penetrating radar full-waveform inversion for field scale moisture mapping: Journal of Hydrology, 424-425, 112-123, doi: 10.1016/j .jhydrol.2011.12.034.

Morey, R. M., A. Kovacs, and G. F. N. Cox, 1984, Electromagnetic properties of sea ice: Cold Regions Science and Technology, 9, 53-75, doi: 10 .1016/0165-232X(84)90048-X.

Morlet, J., G. Arens, E. Fourgeau, and D. Giardi, 1982, Wave propagation and sampling theory - Part I: Complex signal scattering in multilayered media: Geophysics, 47, 203-221, doi: 10.1190/1.1441328.

Mueller, G., 1985, The reflectivity method: A tutorial: Journal of Geophysics, 58, 153-174.

Nelder, J. A., and R. Mead, 1965, A simplex method for function minimization: The Computer Journal, 7, 308-313, doi: 10.1093/comjn1/7.4.308.

Norcor Engineering and Research Ltd, 1975, The interaction of crude oil with Arctic sea ice, Beaufort Sea: Technical Report No. 27. Department of Environment.

Nyland, D., 2004, Profiles of floating ice in Arctic regions using GPR: The Leading Edge, 23, 665-668, doi: 10.1190/1.1776738.

Schmid, L., J. Schweizer, J. Bradford, and H. Maurer, 2015, A synthetic study to assess the applicability of full-waveform inversion to infer snow stratigraphy from upGPR radar data: Geophysics, 81, this issue, doi: 10 .1190/geo2015-0152.1.

Stogryn, A., 1971, Equations for calculating the dielectric constant of saline water: IEEE Transactions on Microwave Theory and Techniques, 19, 733-736, doi: 10.1109/TMTT.1971.1127617.

Stogryn, A., and G. J. Desargant, 1985, The dielectric properties of brine in sea ice at microwave frequencies: IEEE Transactions on Antennas and Propagation, 33, 523-532, doi: 10.1109/TAP.1985.1143610.

Taylor, L., 1965, Dielectric properties of mixtures: IEEE Transactions on Antennas and Propagation, 13, 943-947, doi: 10.1109/TAP.1965 .1138567.

Thomas, D. N., and G. S. Dieckmann, eds., 2010, Sea ice, 2nd ed.: WileyBlackwell.

Tran, A. P., M. Ardekani, M. Reza, and S. Lambot, 2012, Coupling of dielectric mixing models with full-waveform ground-penetrating radar signal inversion for sandy-soil-moisture estimation: Geophysics, 77, no. 3, H33-H44, doi: 10.1190/geo2011-0100.1.

Tsoflias, G. P., and M. W. Becker, 2008, Ground-penetrating radar response to fracture-fluid salinity: Why lower frequencies are favorable for resolving salinity changes: Geophysics, 73, no. 5, J25-J30, doi: 10.1190/1 .2957893 .

Wharton, R. P., G. A. Hazen, R. N. Rau, and D. L. Best, 1980, Electromagnetic propagation logging: Advances in technique and interpretation: Presented at the 55th Annual Fall Technical Conference and Exhibition, Society of Petroleum Engineers, 9267. 